Psicologia Escolar

e Educacional
ARTIGO

DOI: http://dx.doi.org/ 10.1590/2175-35392020214158

Elocid - e214158

\title{
MEDICALIZAÇÃo E PATOLOGIZAÇÃO DA EDUCAÇÃO: DESAFIOS À PSICOLOGIA ESCOLAR E EDUCACIONAL
}

\author{
Ana Carla Cividanes Furlan Scarin ${ }^{1} \mathbb{D}$; Marilene Proença Rebello de Souza ${ }^{1} \mathbb{D}$
}

\begin{abstract}
RESUMO
Este trabalho teve como objeto de estudo a constituição histórica, cultural e social que transforma dificuldades de aprendizagem e de comportamento vividas no processo de escolarização em problemas individuais, de cunho biológico e/ou orgânico. A pesquisa consiste na análise da produção do discurso médico-científico que consolida bases de interpretação do referente às dificuldades de aprendizagem enquanto problemas médicos ou psicológicos, tanto quanto na organização das informações em uma Linha do Tempo, acerca de como os The Diagnostic and Statistical Manual of Mental Disorders (DSM) vêm tratando as dificuldades de aprendizagem desde a sua primeira edição. Para viabilização, foi realizada pesquisa bibliográfica em fontes como MEDLINE, PubMED, LILACS, SCIELO, PsycInfo. Para compilação de dados e explanação dos resultados, apresenta-se a Linha do Tempo dos DSM, a qual se encontra publicada na Biblioteca Virtual de Saúde - BVS PSI, no endereço: http://newpsi.bvs-psi.org.br/uploads/linha\%20 do\%20tempo\%20DSM/linha.html e será periodicamente alimentada.
\end{abstract}

Palavras-chave: educação; medicalização; Psicologia Escolar.

\section{ABSTRACT \\ Medicalization and pathologizing of education: challenges to School and Educational Psychology}

This work had as the object of study the historical, cultural and social constitution that transforms learning and behavior difficulties experienced in the schooling process into individual problems, of biological and / or organic nature. The research consists in the analysis of the medical-scientific discourse production that consolidates bases of interpretation of the referring to the learning difficulties as medical or psychological problems, as well as in the organization of the information in a Timeline, about how The Diagnostic and Statistical Manual of Mental Disorders (DSM) have been treating learning difficulties since its first edition. For feasibility, a bibliographic search was carried out in sources such as MEDLINE, PubMED, LILACS, SCIELO, Psyclnfo. To compile data and explain the results, the DSM Timeline is presented, which is published in the Virtual Health Library - VHL PSI, at: http://newpsi.bvs-psi.org.br/ uploads / line\% 20do\% 20time\% 20DSM / line.html and will be periodically fed.

Keywords: education; medicalization; School Psychology.

\section{Medicalización y patologización de la educación: desafíos a la psicología escolar y educacional \\ RESUMEN}

En este estudio se tuvo como objeto la constitución histórica, cultural y social que transforma dificultades de aprendizaje y de comportamiento vividas en el proceso de escolarización en problemas individuales, de cuño biológico y/u orgánico. La investigación consiste en el análisis de la producción del discurso médico-científico que consolida bases de interpretación del referente a las dificultades de aprendizaje mientras problemas médicos o psicológicos, en la organización de las informaciones en una Línea del Tiempo, acerca de cómo los The Diagnostic and Statistical Manual of Mental Disorders (DSM) vienen tratando las dificultades de aprendizaje desde su primera edición. Para viabilidad, se realizó investigación bibliográfica en fuentes como MEDLINE, PubMED, LILACS, SCIELO, PsycInfo. Para recopilación de datos y explanación de los resultados, se presenta la Línea del Tiempo de los DSM, la cual se encuentra publicada en la Biblioteca Virtual de Salud - BVS PSI, en la dirección: http://newpsi.bvs-psi.org.br/uploads/linha\%20do\%20 tempo\%20DSM/linha.html y será periódicamente alimentada.

Palabras clave: educación; medicalización; Psicología Escolar.

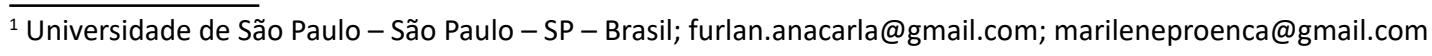




\section{INTRODUÇÃO}

A sociedade contemporânea tem assistido atualmente à classificação desenfreada de comportamentos tanto de crianças e adolescentes quanto de adultos, independente do contexto de ocorrência, como pertinentes à esfera da psicopatologia. Atitudes comuns, reações ocorridas dentro de contextos esperados, comportamentos por vezes executados de maneira um pouco mais intensa têm sido considerados e enfrentados como demonstrações de desestabilidade, de disfunção psíquica e orgânica (Luengo, 2010). A tratativa ao fenômeno tem ocorrido de modo radical: doses maciças de medicação têm sido impostas às crianças, adolescentes e adultos, notadamente crianças, como saída para os inúmeros problemas encontrados, enquanto diagnósticos, nos consultórios médicos.

A justificativa para a vigência da medicalização da sociedade nos chega em forma de diagnósticos, os quais se aferram a eventos particulares, transformando-os em condições gerais e pertença legítima ao convívio diário, que corroboram a sua existência e instigam o encontro de uma saída, uma cura para tais questões. A cura viria pelo uso da medicação. A lógica vigente é, aparentemente, a que supõe a existência de uma derrocada das condições gerais de saúde, em especial de saúde mental, em contrapartida a uma melhoria acentuada no desenvolvimento tecnológico, especialmente na fabricação, controle e distribuição de medicamentos, os quais estariam sendo aprimorados e amplamente distribuídos a fim de auxiliarem como frentes de ação neste contexto. Em suma, a medicação buscaria salvar o que o homem estaria jogando fora: sua saúde física e mental. E garantiria a melhora imediata para aquilo que deteriora tão fácil e reconhecidamente.

Segundo Garrido e Moysés (2011, p. 150), “Medicalizar significa definir, em termos médicos, problemas sociais e buscar sua origem na biologia. Significa também acreditar que o domínio médico pode levar ao domínio da morte...".

Temos também em Guarido (2011) que

Medicalizar um fenômeno teve, tradicionalmente, o sentido geral de reduzir os problemas sóciopolíticos a questões individuais. Além disso, se o objeto da Medicina foi, até certo momento histórico, quase que exclusivamente a investigação sobre as doenças, suas causas e suas terapêuticas, medicalizar um fenômeno ou acontecimento, teve por consequência patologizá-lo. (Guarido, 2011, p. 30).

Há indicações de que o paradigma do entendimento do que venha a ser saúde, e também saúde mental, abordado e consolidado durante os séculos XIX e
$X X$, vem sendo desconstruído à mesma medida que se consolida. Como se houvessem dois movimentos ambivalentes e simultâneos, que se completassem enquanto se negam: enquanto a tecnologia se desenvolve e garante avanços antes inimagináveis, o próprio avanço assegura o retorno à dependência e condições sub-humanas de vida.

Souza (2010), ao discutir a questão da utilização de medicamentos do ponto de vista do processo de escolarização, considera que o aumento na prescrição de Metilfenidato reflete também uma necessidade de a escola se repensar e rever as formas como tem constituído suas relações de ensino e de aprendizagem: que escola temos oferecido às crianças e adolescentes? A pesquisadora considera que a necessidade do tratamento medicamentoso não pode ser a primeira via de análise das dificuldades na escolarização, sendo fundamental compreender a gama de condições em que determinados comportamentos acontecem, principalmente diante das grandes dificuldades que o sistema de ensino no Brasil ainda enfrenta.

Diante do posto, podemos considerar que uma das grandes dificuldades encontra-se ligada à compreensão do fenômeno chamado dificuldade de aprendizagem. 0 fato é que esse qualificativo aparece em nossa linguagem, em outros momentos, talvez com designações um pouco diferentes, há bastante tempo.

Assim, podemos entender que o que está em questão nesse momento é o psicodiagnóstico, ou a noção de sujeito psicológico que estamos construindo e sustentando através desta forma de abordagem. Que subjetividade está sendo considerada? Do ponto de vista da ontogênese, quem é o sujeito dessa definição de dificuldade de aprendizagem?

Temos em Souza (2007) uma profícua discussão acerca de psicodiagnóstico. Segundo a pesquisadora,

Ao considerar que as causas da queixa escolar encontram-se no psiquismo (problemas emocionais) ou no rebaixamento intelectual (deficiência mental), que, é importante ressaltar, a maioria das vezes as crianças não apresentam, continuamos eximindo o sistema escolar da participação e/ou produção dessas dificuldades. Desconsiderar a produção do fracasso no conjunto de relações do processo de escolarização dificulta propor ações que venham a modificar, pelo menos minimamente, as relações escolares. (Souza, 2007, p. 52).

Assim, a sinalização parece vir no sentido de apontar para uma situação em que o sujeito psicológico que aprende, em sua subjetividade, encontra-se reduzido a uma leitura de saúde, realizada através da linguagem médica, que abduz questões referentes à complexida- 
de das situações escolares e condições educacionais, tratando-as como coadjuvantes, quando considerado o processo ensino-aprendizagem.

Concomitante ao fenômeno abordado e às perspectivas e condições de identificação e intervenção junto ao mesmo, temos observado uma dificuldade acentuada na sociedade contemporânea no que se refere a lidar com conflitos e contrariedades presentes nos relacionamentos. Como se existisse, pari passu às ações humanas, uma miopia irreversível que dotasse as pessoas da necessidade de garantias quanto ao andamento de ações e resultados, ou asseguramento quanto aos resultados diante do esforço necessário às ações.

As dificuldades dos relacionamentos estariam determinando ambiguidades na linguagem, na postura e mesmo na interpretação e aplicação dos padrões morais vigentes. A necessidade de padronizar, encontrando dentre os fatores ligados à situação um item que figure como explicação cabal, amortizando todos os outros elementos em questão, nos parece premente. Estabelecida e eleita a categoria, por meio de uma categorização simples, tudo o mais se torna passível de exclusão enquanto forma componente do "problema" e solução possível junto ao mesmo como "fato". Conforme Bleger (1984, p. 54): "O fator mais difícil de manejar não é o conflito, mas a ambiguidade que age como um amortizador ou 'des-desenhador' dos conflitos."

Tudo isso nos leva a considerar em que proporção os desalinhamentos referentes aos equívocos vigentes e, portanto, de alguma forma permitidos, existam. Já que a doença mental anda assolando a população, se manifestando em várias faixas etárias, que compreensão temos tido de saúde e de saúde mental? E quanto aos fenômenos educacionais, o que temos a dizer? O que é hoje a dificuldade na aprendizagem das crianças em idade escolar? E como abarcar os inúmeros diagnósticos concluídos como de transtorno de déficit de atenção e hiperatividade - TDAH?

\begin{abstract}
Segundo Luengo (2010)
O fracasso escolar é expressão institucionalizada, presente na escola como problema, cuja existência - que já parece inquestionável - opera produzindo saber. Porém, se antes o aluno fracassado era aquele que apresentava "desinteresse", "indisciplina" e "falta de educação", na atualidade é o aluno que apresenta algum tipo de disfunção cerebral de origem genética, capaz de causar deficiências e desordens no comportamento. A ciência médica atravessou o âmbito escolar e hoje a escola é um dispositivo institucionalizado, que foi produzido e produziu relações de saber-poder. (Luengo, 2010, p. 61).
\end{abstract}

A fim de dar consistência à discussão e pensarmos acerca de como a questão diagnóstica vem sendo viabilizada, trazemos para o cenário a abordagem fornecida pelo DSM, ou Manual Diagnóstico e Estatístico de Transtornos Mentais (The Diagnostic and Statistical Manual of Mental Disorder), de origem norte-americana, cuja publicação vem obtendo aceitação maciça, notadamente da parte dos psiquiatras, que têm feito de suas orientações diagnósticas o eixo ao conduzir suas atuações junto aos pacientes. Podemos relatar, acerca do DSM, que sua primeira edição consta como publicação em 1952, pela Associação Americana de Psiquiatria (American Psychiatric Association, APA). Demandas vindas de hospitais psiquiátricos, provenientes de situações decorrentes da II Guerra Mundial, solicitaram providências da parte de médicos e psicólogos. $\mathrm{O}$ aparecimento de comportamentos entendidos como frutos de desordem mental, ocorridos durante a guerra e após seu término, levou, assim, à sua elaboração. Foram nomeadas 106 categorias de desordem mental, segundo Aiex Neto (2012).

Ainda sobre a história do DSM, as experiências com questões de saúde mental levaram os norte-americanos a investirem na coleta informações de caráter estatístico, a fim de se compreender como o fenômeno doença mental se manifestava, enquanto patologia, nos norte-americanos, através dos números. O primeiro passo rumo à efetivação de meios para suprir esta necessidade foi a realização de um censo, em 1840, garimpando dados estatísticos acerca de duas categorias: idiotia e insanidade. Em um segundo censo, realizado em 1880, foram observadas sete categorias de doença mental: mania, melancolia, monomania, demência, paresia, dipsomania e epilepsia. Entra em campo, em 1917, a então chamada Associação Médico-psicológica Americana (que, em 1921, passa a se chamar Comitê de Estatística da Associação Psiquiátrica Americana) que, junto com a Comissão Nacional de Higiene Mental, realizou uma coleta de dados para fins estatísticos ligados aos hospitais psiquiátricos. Desse trabalho, que foi realizado em conjunto com a Academia de Medicina de Nova York, resultou a primeira edição da Nomenclatura Classificada e Estandartizada das Doenças da Associação Médica Americana. Couberam aqui, como matéria-prima para a coleta de dados, pacientes psiquiátricos e neurológicos internados (Associação Americana de Psiquiatria [APA], 1995).

O Exército, pelo envolvimento em períodos de guerra, desenvolveu uma nomenclatura mais aperfeiçoada, cuja publicação quase coincidiu com a publicação da CID 6 pela Organização Mundial de Saúde. O passo seguinte foi que o Comitê de Nomenclatura e Estatística da Associação Psiquiátrica Americana tomou para si a ação e desenvolveu uma variante da CID 6, com o apoio do Exército, que consistiu na primeira edição do Manual Diagnóstico e Estatístico de Transtornos Mentais (1952) 
(APA, 1995).

Ainda assim, a necessidade de levantar estatisticamente e nomear dados referentes à doença mental persistiu, e daí para a frente o mundo assistiu ao surgimento progressivo das citadas edições e, com elas, um aumento significativo do número de patologias nomeadas e elencadas, conforme assinalado acima.

Podemos então enfatizar que buscar a lógica delineada pelos DSM auxilia a compreender como os pontos de vista acerca da Psicologia e seu objeto de estudos vêm sendo apreendidos pela humanidade. $O$ exercício de abarcar o conhecimento acerca do psicológico é também o exercício de consolidar uma prática fortalecedora do subjetivo enquanto expressão do humano, e não do enraizamento em pressupostos reducionistas. Portanto, buscar a complexidade junto à leitura do psicológico através destes Manuais sustenta o desvelar dos pontos de vistas contemporâneos acerca do humano em movimento (Aiex Neto, 2012).

Percebemos também o quanto esta prisão na ambiguidade reafirma a aplicação de uma lógica de raciocínio empobrecida. $O$ estreitamento das correlações possíveis, proveniente do reducionismo, dilui a capacidade de percebermos e nos conscientizar a respeito dos fenômenos presenciados (Bleger, 1984). As perdas são irreparáveis, pois nos limitamos a estagnar em um universo que, pela impossibilidade de evolução, não nos representa filogenética ou ontogeneticamente.

Foucault (2008) vem nos lembrar: "A loucura só existe em cada homem porque é o homem que a constitui no apego que ele demonstra por si mesmo e através das ilusões que ele alimenta" (p.24). A Psicologia surgiu para quebrar paradigmas, considerando que contribui em conceituações historicamente importantes. Descobrir a vida enquanto processo e saber pensá-la deste ponto de vista, consiste em um dos grandes desafios desta área ainda em desenvolvimento.

\section{MÉTODO}

O psicodiagnóstico das dificuldades de aprendizagem pela ótica do The Diagnostic and Statistical Manual of Mental Disorders (DSM)

O aumento excessivo no número de psicodiagnósticos, notadamente nos últimos 20 anos, levou-nos ao questionamento acerca do motivo pelo qual isso vem acontecendo, tanto quanto acerca de suas consequências. Assim, realizamos uma pesquisa junto ao Departamento de Psicologia Escolar e do Desenvolvimento Humano, vinculado ao Instituto de Psicologia, da Universidade de São Paulo/SP, que buscou conhecer o discurso médico-científico que transforma questões de comportamento em problemas de aprendizagem. Para tal, nos apropriamos dos textos dos The Diagnostic and Statistical Manual of Mental Disorders, ou Manual Diagnóstico e Estatístico dos Transtornos Mentais, conhecido como DSM, a fim de acompanharmos o desenrolar das características diagnósticas descritas nos Manuais.

A pesquisa foi realizada nos anos de 2014 a 2016, e teve como problematização a questão do aumento substancial do número de diagnósticos referentes a dificuldades de aprendizagem, notadamente dentro do apresentado pelos DSM como proposta, critérios diagnósticos e quadros clínicos. A busca foi realizada por meio de palavras-chave nas bases de dados MEDLINE, PubMED, LILACS, SciELO, Psyclnfo. Buscando mapear a evolução dos quadros diagnósticos, organizou-se uma Linha do Tempo, cujo objetivo é o de comportar muitas informações que podem ser visualizadas simultaneamente, proporcionando uma maneira profícua de se estabelecer comparações entre os elementos que venham a compor a mesma.

Nesta Linha do Tempo, que foi desenvolvida por Analista de Sistemas ${ }^{1}$, organizou-se o conteúdo referente a Dificuldades de Aprendizagem presente desde a primeira edição publicada do DSM, datada de 1952, até a última edição, publicada em 2013. O conteúdo foi distribuído de acordo com a organização dos próprios Manuais, a começar pela dificuldade indicada, seguida de sua descrição que, nos Manuais, se dá através de itens, ou seja, cada quadro diagnóstico vem descrito de acordo com os itens, em sequência. Os itens escolhidos para constarem enquanto dados a serem comparados foram: Características essenciais, Características associadas, Prevalência, Tipos (quando há), Critérios diagnósticos. Não foram elencados todos os itens de cada quadro, e a opção pelos itens aconteceu com base nos argumentos em questão, trazidos nos manuais como forma de explicar a evolução de cada quadro e a significância dos mesmos. Assim, cada quadro diagnóstico referente a dificuldades de aprendizagem foi lançado na Linha do tempo, manual a manual, até que fosse possível visualizar a sua evolução com as respectivas descrições, dadas a partir dos citados itens.

Concomitantemente, foi realizado um levantamento amplo de textos que tenham como conteúdo a validação ou a crítica aos conteúdos dos DSM. Os textos foram garimpados a partir do ano de publicação da primeira edição, notadamente 1952. Não foi possível encontrar textos muito antigos, constando como mais velho um texto datado de 1967. O levantamento constou de teses, dissertações, livros, artigos científicos, entrevistas a jornais e revistas, sempre com o foco no conteúdo, considerado a partir da abordagem à defesa ou crítica aos DSM. Esse levantamento também consta na Linha do Tempo, estando apresentado Manual a Manual, com o intuito de enfatizar uma vez mais a evolução do

\footnotetext{
${ }^{1}$ O projeto da concepção de uma Linha do Tempo online foi fruto de trabalho realizado pelo Analista de Sistemas Alex dos Santos, com apoio da FAPESP.
} 
conteúdo dos mesmos e a argumentação que sustenta os posicionamentos dos autores.

A citada Linha do Tempo, contendo a relação de publicações, encontra-se publicada na Biblioteca Virtual de Saúde - BVS Psicologia Brasil, no endereço: http://newpsi.bvs-psi.org.br/uploads/linha\%20do\%20 tempo\%20DSM/linha.html

O objetivo da pesquisa foi investigar, junto à literatura priorizada, os apontamentos realizados em relação a questões referentes ao processo diagnóstico e, por conseguinte, compreender do ponto de vista da perspectiva do entendimento do ser humano enquanto ser em permanente desenvolvimento e pleno de capacidades, também questões envolvendo patologização de comportamentos e, notadamente, medicalização da vida.

O recorte para levantamento dos dados centra-se no conjunto de textos dos DSM referentes aos diagnósticos em dificuldades de aprendizagem, tendo em vista que os Manuais trabalham com diagnósticos em diversas áreas. É sabido, portanto, que, em 1952, a sociedade norte-americana viu surgir a primeira edição do Diagnostic and Statistical Manual of Mental Disorders, ou Manual Diagnóstico e Estatístico de Transtornos Mentais, identificado hoje também pelas suas iniciais, DSM. Este Manual consta de nove edições, a saber:

$$
\begin{aligned}
& \text { DSM I: publicado em 1952; } \\
& \text { DSM I - Special Supplement - publicado em } \\
& 1965\left(^{*}\right) \text {; } \\
& \text { DSM II - publicado em 1968; } \\
& \text { DSM II - 6th Printing Chance - publicado em } \\
& 1973\left({ }^{*}\right) \text {; } \\
& \text { DSM III - publicado em 1980; } \\
& \text { DSM III - Review - publicado em 1987; } \\
& \text { DSM IV - publicado em 1994; } \\
& \text { DSM IV - Text Review - publicado em 2000; } \\
& \text { DSM V - publicado em } 2013 .
\end{aligned}
$$

Nesta pesquisa, temos como base de consulta e análise as edições I (APA, 1952), II (APA, 1968), III (APA, 1980), III-R (APA, 1989), IV (APA, 1994, 1995), IV-TR (2002) e V $(2013,2014)$. Analisaremos, a seguir, os principais resultados da pesquisa e suas implicações na produção de diagnósticos no âmbito das dificuldades de aprendizagem.

\section{RESULTADOS E DISCUSSÃO}

É facilmente constatável, a partir dos dados apresentados na Linha do Tempo, o aumento palpável no número de diagnósticos, consideradas as questões referentes às dificuldades de aprendizagem. Tomando por base a Primeira Edição do Manual Diagnóstico e Estatístico dos Transtornos Mentais, publicada em 1952, e a última, publicada em 2013, muitas foram as patologias surgidas, cada qual buscando aprofundamentos em relação ao pautado nas apresentações das patologias em edições anteriores. É possível observar o dito no desenrolar das referências às mesmas em edições do DSM III-R (1987) e no DSM IV-TR (2000). A justificativa para as ênfases clínicas dadas na edição do DSM V (2013) surge no sentido de salientar o impacto social de cada doença, e dessa abordagem decorrem as descrições desta e as correlações com as comorbidades, tanto quanto os traços presentes, considerada a modalidade clínica de cada patologia.

Chancelando esta afirmativa, há a discussão acerca das descrições realizadas, as quais privilegiam uma classificação das características das patologias chamadas, no DSM V, de Características Essenciais e Características Associadas. As primeiras revelam os comportamentos levando em conta os seus traços e mostram, ao longo das edições dos DSM III (1980) e IV-TR (2000), uma certa repetição destes, tanto quanto nenhuma justificativa estatística ou conceitual, do ponto de vista da constituição da patologia, para o que se mantém e o que é reapresentado com modificações. A discussão qualitativa não aparece em momento algum da apresentação das patologias e distinção de seus traços componentes dos quadros clínicos. Em Características Associadas, há a justaposição da patologia somada a outros quadros diagnósticos, primando por uma descrição em que as questões classificatórias se inter-relacionem. Há aqui, também, a ausência de justificativas ou explanações abordando pesquisas científicas, dados estatísticos, debates, que explicitem cientificamente as inter-relações trazidas a público.

As descrições se mantêm, enquanto tais, no item Prevalência, em que são abordados índices estatísticos e epidemiológicos das patologias. Os dados estatísticos se referem aos vigentes nos Estados Unidos predominantemente, sendo apresentados poucos dados em relação aos demais países. Não aparecem aqui, igualmente, explanações científicas acerca das pesquisas que fundamentem esses dados, ou notícias de discussões clínicas que possam contrapor o apresentado. As variações quanto ao aparecimento dos quadros clínicos por faixa etária também comparecem, mas está aqui mantida a ausência de apresentação dos procedimentos que fundamentariam cientificamente $o$ material estatístico e clínico abordados.

Outro aspecto a ser enfatizado diz respeito ao item Critérios Diagnósticos que, nas edições do DSM identificadas como III (1980), III-R (1987), IV (1994) e IV-TR (2000), figuram como os traços da doença, sendo inclusive elencados e sistematizados dentro dessa condição. Importante considerar também que na edição do DSM identificada como V (2013), os Critérios Diagnósticos figuram como sintomas, supostamente buscando atrelar os traços da patologia à sua sintomatologia. Esse contexto leva a um aprofundamento da reflexão sobre a fundamentação das psicopatologias, uma vez que 
parecem, aqui, estarem amalgamadas à etiologia, à semiologia e à consequente discussão da patologia em si, pois as fronteiras entre os campos científicos citados se mostram sem contorno, gerando ambiguidades quanto à compreensão da procedência e evolução da patologia, tanto quanto das questões clínicas do contexto observado. As doenças clinicamente apresentadas indicam, a partir dessa abordagem, pertencer ao indivíduo, dificultando a leitura do adoecimento enquanto um processo, o que dificulta, por sua vez, a discussão acerca do que tange os limites entre saúde e doença.

$\mathrm{O}$ que salta aos olhos, conforme vem sendo discutido, é que o nome do DSM é Manual Diagnóstico e Estatístico de Transtornos Mentais e, a despeito do termo "estatístico" nominalmente presente, não há apresentação e/ou discussão acerca dos aspectos estatísticos apresentados ou prospectados, limitando as apresentações à indicação dos dados, considerados tão somente do ponto de vista numerário e classificatório, pautados por um olhar clínico dos comportamentos humanos.

Prosseguindo com a reflexão, pode-se considerar o que é acarretado pela ausência da discussão acerca das questões etiológicas na área da psicopatologia, a qual é dotada de enorme complexidade e, assim, de muitos pontos ainda obscuros. As questões ideológicas, certamente, permeiam essa seara da obscuridade, apontando uma tendência possível à confusão entre fenômeno patológico e seu hospedeiro ideológico. 0 que se perde em meio a essa proposta classificatória maciça é a abertura para discussão acerca da lógica do sofrimento mental e, por conseguinte, das questões concernentes e fundantes do que tange a relação saúde/ doença. Esse aspecto fica reduzido à mera possibilidade de localização nominal da patologia em questão, quando há um processo psicodiagnóstico em curso.

Voltando à Linha do Tempo, e com foco agora no levantamento bibliográfico realizado paralelamente à sua confecção, foram encontradas, no período estudado, 250 publicações concernentes ao tema das dificuldades de aprendizagem. $O$ critério utilizado na busca do material do levantamento bibliográfico foi: textos que abordassem questões teóricas e práticas acerca do conteúdo dos DSMs, tanto corroborando seus pontos de vista quanto criticando-os.

Em números, os resultados do citado levantamento foram:

- Textos favoráveis aos DSMs: 15 livros, 15 entrevistas, 94 artigos, 02 dissertações, 02 teses. Total: 128 publicações;

- Textos não favoráveis aos DSMs: 20 livros, 14 entrevistas, 78 artigos, 05 dissertações, 05 teses. Total: 122 publicações.

Considerando o conteúdo, as publicações favoráveis aos textos dos DSMs contemplam uma abordagem biologicista do comportamento e afeto humanos. A questão neurológica como causa do comportamento humano e fundante do afeto é explanada de maneira clara, trazendo à baila a consequência dessa maneira de compreender o funcionamento mental humano: o tratamento medicamentoso. Quanto à autoria, predominam médicos, sejam psiquiatras, neurologistas, e mesmo psicólogos atuantes na área da neuropsicologia. A discussão de comportamento e afeto realizada nesse formato traz no seu bojo a inserção da biologia como determinante desses aspectos tão humanos, e o resultado é a interferência desses pontos de vista profissionais no tocante a questões não só da saúde, mas da educação e da socialização.

A escola tem apresentado enorme suscetibilidade a esses aspectos diagnósticos. A criança e o adolescente "que não aprendem" são frequentemente encaminhados ao médico, que na maioria das vezes, realiza exames neurológicos e solicita avaliações neurospicológicas os quais, uma vez concluídos, afirmam ter essa criança ou adolescente algo como "risco para TDAH", "risco para Dislexia", "risco para Transtorno Específico de Aprendizagem", "risco para Transtorno Opositivo Desafiador", ou mesmos esses citados quadros já consolidados (no caso, o diagnóstico é apresentado sem a palavra "risco'). Como se sabe, são quadros clínicos descritos de maneira classificatória no DSM, e a repercussão desse diagnóstico nas vidas dos diagnosticados vai além da questão social pois, uma vez diagnosticado, o próximo passo é recorrer à medicação como forma de dar conta da sintomatologia do contexto clínico traçado pela abordagem do DSM. Questões referentes a isso foram discutidas, em números, ao início deste artigo.

Lançando o olhar para as publicações contrárias ao conteúdo abordado nos DSMs, essas vêm de encontro à biologização do comportamento e do afeto, e tecem críticas à patologização e medicalização da educação e da sociedade. Há a defesa do considerar-se o sujeito ontológico, a singularidade de cada um, e a lógica do sofrimento mental reconhecendo-o como um processo, e não apenas como um resultado. Os textos coletados foram escritos por profissionais de diversas áreas: psicologia, fonoaudiologia, medicina, pedagogia. Vale ressaltar a entrevista dada por Allen Frances, chefe da equipe de coordenação e elaboração do DSM IV (APA, 1994), na qual Frances afirma categoricamente que o TDAH não existe (Frances, 2014).

Assim, pode-se constatar que existe uma abordagem classificatória, resultado de um contexto em que a discussão clínica acontece, segundo o sinalizado no decorrer do texto do DSM V, a partir do que os autores consideram "o impacto social da doença" (APA, 2014, p.15). Diante do posto, a questão dos sintomas e da nosografia, considerada do ponto de vista descritivo, 
inviabiliza a discussão acerca da etiologia das psicopatologias e faz fenecer, enquanto ponto de partida, a busca pela compreensão da lógica do sofrimento mental.

A classificação e sistematização de dados clínicos como abordagem diagnóstica reduz a amplitude da discussão acerca do sujeito ontológico em questão bem como o entendimento do que seja dificuldade de aprendizagem. Tem-se, assim, explicado os altos índices de prescrição de medicação a crianças, adolescentes e mesmo adultos que "não aprendem" e, portanto, o crescimento exponencial do que hoje chamamos de medicalização da educação. Faz-se também referência aqui, às questões do sistema de educação brasileiro, o qual adere à leitura do ser aprendente nos citados termos, centrando no ponto de vista médico quando da necessidade de tomadas de decisões educacionais e escolares.

Destaca-se, portanto, a importância de compreender o processo de escolarização ao invés de focar nas dificuldades de aprendizagem, conforme Souza (2010):

Ao considerar o processo de escolarização, a Psicologia Escolar passa a enfatizar a necessidade de que a escola é o espaço em que relações sociais e individuais se articulam numa rede de relações complexas e que precisam ser analisadas como tal. (Souza, 2010, p. 60).

Absorver a complexidade da rede escolar, tanto quanto do que dá base de sustentação a relações produtivas é, portanto, a tarefa enquanto reflexão e ação do psicólogo na escola nesse momento.

\section{CONCLUSÃO}

A abordagem biologicista/organicista, que transforma sintomas fisiológicos em comportamento (Frances, 2014), exclui a possibilidade de compreensão do ser humano que sofre e, por conseguinte, da natureza do sofrimento. Ainda quanto a esse aspecto, exclui a condição de se hipotetizar sobre as reais causas do sofrimento mental, reduzindo o que pressupõe amplitude de entendimento acerca do humano, pois desconsideram-se aspectos tais como a saúde mental da psicomotricidade, o desenvolvimento psicomotor em si, e a complexidade do desenvolvimento cognitivo, para citar alguns pontos passíveis de reflexão. A ambiguidade está presente, e transparece na reflexão de Lewontin, Rose e Kamin (1984), ao afirmarem que os sociobiologistas, categoria de cientistas que pretendem implementar o biologismo como eixo de reflexão e atuação no tocante a questões de saúde, se pautam nos seguintes pontos: dividem o organismo para explicá-lo; confundem categorias metafísicas com objetos concretos; confundem metáforas com entidades reais; combinam diferentes fenômenos, alocando-os no mesmo lugar (Lewontin et al., 1984). Talvez se possa considerar que a busca por pontos que priorizem o enfraquecimento do semelhante pode ser uma estratégia que, induzindo ao erro moral, abra espaço para a vigência e o exercício de algum hospedeiro ideológico que esteja à espreita.

Temos, portanto, muitos desafios pela frente, mas consideramos que, do ponto de vista da Psicologia Escolar e Educacional, o fundamental é levarmos em conta que precisamos cada vez mais conhecer o processo de escolarização. Processo este, complexo, construído nas relações sociais, culturais, pedagógicas, interacionais, institucionais, atravessado pelas políticas educacionais e por um conjunto de circunstâncias históricas. É fundamental conhecer o processo de aprendizagem no seu cotidiano, vivo, real, concreto. As pesquisas da área que se propõem a viver e conviver com a escola e com seus atores trouxeram e trazem importantes propostas para a escolarização que visam superar o olhar individualizante, patologizante e preconceituoso que ainda se vê presente na escola em relação a dificuldades enfrentadas, principalmente, no processo de leitura e escrita. São inúmeros trabalhos que apresentam alternativas não medicalizantes, centradas nos processos de aprendizagem, desenvolvimento, escolarização, conforme sistematiza o artigo de Souza et al. (2014). A área construiu as suas Referências Técnicas para Atuação de Psicólogas(os) na Educação Básica (2019) em que apresenta as principais propostas de trabalho a serem desenvolvidas.

No que tange ao processo de avaliação psicológica, o avanço da discussão deste tema na área também é considerável. As propostas tiveram início nos anos 1990 e propuseram alternativas importantes por meio de referenciais teóricos críticos e que levam em conta a avaliação psicológica enquanto processo de compreensão das relações escolares e não apenas um olhar clínico sobre a criança que supostamente não aprende ou não apresenta comportamentos desejáveis no ambiente escolar. Em livro organizado por Facci, Leonardo e Souza (2019) é possível observar os avanços da Psicologia Escolar e Educacional no âmbito da avaliação psicológica, por meio de práticas interativas e interventivas de trabalho junto às escolas, professores e estudantes. Questionam, portanto, uma visão diagnóstica que desconsidera a escola, os processos de aprendizagem, as relações intersubjetivas presentes na constituição do conhecimento e que geram o desenvolvimento humano. Os estudos revelam os fundamentos teórico-metodológicos de compreensão do processo de aprendizagem, das formas de apropriação da leitura e da escrita, baseados em concepções histórico-culturais e que possibilitam compreender a dimensão biológica como constitutiva do humano nas suas relações de aprendizagem.

Diante de uma massa crítica que compõe hoje o conhecimento em Psicologia na sua relação com o campo da Educação Básica e Superior, é importante ressaltar o compromisso ético-político do(a) psicólogo(a) com 
a ciência, com a escola democrática e com uma práxis libertadora e emancipatória. Não podemos continuar nos calando diante de diagnósticos que selam destinos, selam trajetórias de vida. Cabe a nós, enquanto psicólogos e psicólogas, abrir cada vez mais os caminhos do conhecimento e de uma prática crítica, consequente e ética.

\section{REFERÊNCIAS}

Aiex Neto, J. E. (2012). Psiquiatria sem alma. Curitiba, PR: Travessia dos Editores.

American Psychiatric Association [APA]. (1952). Diagnostic and Statistical Manual of Mental Disorders -DSM I. Washington D/C: APA.

American Psychiatric Association [APA]. (1968). Diagnostic and Statistical Manual of Mental Disorders - DSM II. Washington D/C: APA.

American Psychiatric Association [APA]. (1980). Diagnostic and Statistical Manual of Mental Disorders - DSM III. Washington D/C: American Psychiatric Association.

American Psychiatric Association [APA]. (1989). Manual de diagnóstico e estatística de distúrbios mentais - DSM III Revisão (Barbosa, L. H. S. revisão técnica; Giordano Júnior, S.,Trad.). São Paulo: Manole.

American Psychiatric Association [APA]. (1994). Diagnostic and Statistical Manual of Mental Disorders - DSM IV. Washington D/C: American Psychiatric Association.

American Psychiatric Association [APA]. (1995). Manual diagnóstico e estatístico de transtornos mentais - DSM IV (D. Batista, Trad.). Porto Alegre: Artes Médicas.

American Psychiatric Association [APA]. (2002). Manual diagnóstico e estatístico de transtornos mentais - DSMIVRevisado (Dornelles, C., Trad.). Porto Alegre: Artes Médicas.

American Psychiatric Association [APA]. (2013). Diagnostic and Statistical Manual of Mental Disorders - DSM 5. Washington D/C: American Psychiatric Association.

American Psychiatric Association [APA]. (2014). Manual diagnóstico e estatístico de transtornos mentais- DSM 5. Porto Alegre: Artmed, 2014.

Bleger, J. (1984). Psico-higiene e psicologia institucional. Porto Alegre: Artes Médicas.

Conselho Federal de Psicologia (2019). Referências Técnicas para Atuação de Psicólogas(os) na Educação Básica. Brasília: CFP. Recuperado em 20 de abril de 2020 de https://site.cfp.org.br/wp-content/uploads/2019/08/ EducacaoBASICA_web.pdf
Facci, M. G. D.; Leonardo, N. S. T. (Org.); Souza, M. P. R. (Eds). (2019). Avaliação psicológica e escolarização: contribuições da psicologia histórico-cultural. 1. ed. Teresina: EDUFPI.

Foucault, M. (2008). História da loucura. São Paulo: Perspectiva.

Frances, A. (2014, 27 de setembro). Transformamos problemas cotidianos em transtornos mentais (entrevistado por M. P. O.). El País. Recuperado em 20 de abril de 2020 de https://brasil.elpais.com/brasil/2014/09/26/ sociedad/1411730295_336861.html

Guarido, R. (2011). A biologização da vida e algumas implicações do discurso médico sobre a educação. In Conselho de Psicologia de São Paulo; Grupo Interinstitucional De Queixa Escolar (Eds.), Medicalização de crianças e adolescentes: conflitos silenciados pela redução de questões sociais a doenças de indivíduos, (vol. 1, pp. 27-40).São Paulo: Casa do Psicólogo.

Lewontin, F. C.; Rose, S.; Kamin, L. J. (1984). Not in our genes: ideology, and human nature. United States: Peguin Press Science.

Luengo, F. C. (2010). A vigilância punitiva: a postura dos educadores no processo de patologização e medicalização da infância. São Paulo: Editora UNESP; São Paulo: Cultura Acadêmica.

Garrido, J.; Moysés, M. A. A. (2011). Um panorama nacional dos estudos sobre a medicalização da aprendizagem de crianças em idade escolar. In Conselho de Psicologia; Grupo Interinstitucional de Queixa Escolar (Eds.), Medicalização de crianças e adolescentes: conflitos silenciados pela redução de questões sociais a doenças de indivíduos (vol. 1, pp. 149-162). São Paulo: Casa do Psicólogo.

Souza, M. P. R. (2007). Prontuários revelando bastidores: do atendimento psicológico à queixa escolar. In Souza, B. P. (Ed.), Orientação à queixa escolar, (vol. 1, pp. 27-58). São Paulo: Casa do Psicólogo.

Souza, M. P. R. (2010). Retornando à patologia para justificar a não aprendizagem escolar: a medicalização e o diagnóstico de transtornos de aprendizagem em tempos de neoliberalismo. In Conselho Regional de Psicologia de São Paulo; Grupo Interinstitucional de Queixa Escolar (Eds.), Medicalização de Crianças e Adolescentes: conflitos silenciados pela redução de questões sociais à doença de indivíduos (vol. 1, pp. 57-68). São Paulo: Casa do Psicólogo.

Souza, M. P. R.; Barbosa, D. R.; Ramos, C. J. M.; Yamamoto, K.; Calado, V. A. ; Lima, C. P. (2014). Atuação do psicólogo na educação: análise de publicações científicas brasileiras. Psicologia da Educação (Impresso), v. 38, pp. 123-138. 